\title{
Neuropsychological outcome of cognitive training in mild to moderate dementia : A randomized controlled trial
}

\section{Kallio, Eeva-Liisa}

2021-07-03

Kallio , E-L , Hietanen , M , Kautiainen , H \& Pitkälä , K H 2021 , ' Neuropsychological outcome of cognitive training in mild to moderate dementia : A randomized controlled trial ', Neuropsychological Rehabilitation, vol. 31 , no. 6 , pp. 935-953 . https://doi.org/10.1080/09602011.2020.1749674

http://hdl.handle.net/10138/333611

https://doi.org/10.1080/09602011.2020.1749674

acceptedVersion

Downloaded from Helda, University of Helsinki institutional repository.

This is an electronic reprint of the original article.

This reprint may differ from the original in pagination and typographic detail.

Please cite the original version. 


\section{TITLE PAGE}

Neuropsychological outcome of cognitive training in mild to moderate dementia: A randomized controlled trial

Eeva-Liisa Kallio, $\mathrm{PhD}^{\mathrm{a}, \mathrm{b}}$

Marja Hietanen, $\mathrm{PhD}^{\mathrm{b}}$

Hannu Kautiainen, $\mathrm{PhD}^{\mathrm{a}}$

Kaisu H. Pitkälä, MD, $\mathrm{PhD}^{\mathrm{a}}$

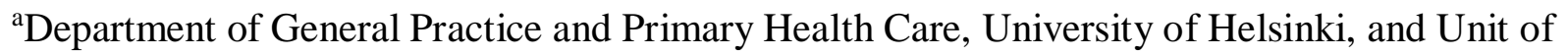
Primary Health Care, Helsinki University Hospital, Helsinki, Finland

${ }^{\mathrm{b} C l i n i c a l}$ Neurosciences, Neuropsychology, University of Helsinki and Helsinki University Hospital, Helsinki, Finland

\section{Corresponding author:}

Dr. Eeva-Liisa Kallio

Neurocenter, Neuropsychology, University of Helsinki and Helsinki University Hospital, P.O. Box 302, FI-00029 HUS, Finland

Tel: +358-9-47176148, Fax: +358-9-47174088

E-mail: eeva-liisa.kallio@hus.fi 


\begin{abstract}
Effectiveness of a 12-week cognitive training (CT) program for community-dwelling patients with dementia was evaluated on various cognitive functions (attention, memory, executive functions and reasoning) and psychological well-being (PWB). A single-blind randomized controlled trial was conducted in adult day care centers in Helsinki, Finland. Participants $(N=147)$ were older individuals with mild to moderate dementia living at home and attending day care (mean age 83 years, $72 \%$ female, $63 \%$ at mild stage of dementia). The intervention group $(n=76)$ received systematic CT for 45 minutes twice a week while the control group $(n=71)$ attended day care as usual. The cognitive and psychological outcomes were measured at baseline, and followed up at 3 and 9 months. No differences between the two groups in changes of any of the cognitive functions, or PWB over time were found. We observed a positive trend at 3 months in the change for PWB favoring the intervention group, but no significant interaction effect was found $(p=.079 ; d=-0.31)$. Thus, systematic CT appears to have no effect on neuropsychological outcomes of cognitive functioning and PWB in older adults who already have dementia.
\end{abstract}

Keywords: cognition, cognitive training, dementia, executive functions, psychological well-being 


\section{INTRODUCTION}

The worldwide prevalence and the associated costs of Alzheimer's disease (AD) and other neurodegenerative disorders are ever increasing. ${ }^{1}$ Current pharmacological treatments provide limited benefits, and efforts have been made to identify effective non-pharmacological approaches to prevent or slow down the symptoms of neurodegenerative disorders. ${ }^{2}$ Cognitive dysfunction is a key feature in $\mathrm{AD}$ and other dementia. Numerous activities of daily living and independent behavior rely upon memory, executive and other essential cognitive functions, which deteriorate progressively in different types of dementia. ${ }^{3-5}$ Executive functioning encompasses several cognitive skills, such as updating working memory representations, paying selective attention, planning, and inhibitory self-control. ${ }^{6,7}$ Rehabilitation techniques designed to improve such skills are likely to support independence and quality of life of persons with dementia. ${ }^{8}$

Treatment modalities specifically designed to target cognitive impairment include general cognitive stimulation, practice-oriented cognitive training (CT), and individualized cognitive rehabilitation. ${ }^{9}$ CT is a feasible, low-cost, and face-valid training method used in various rehabilitation contexts. It refers to a behavioral intervention strategy the objective of which is to remediate deterioration in memory, attention, and other cognitive domains using either restorative or compensatory methods. ${ }^{9-}$

${ }^{11}$ When the aim is restorative, CT involves guided practice on various tasks reflecting specific cognitive functions. ${ }^{9}$ Training is typically offered using predesigned paper-and-pencil exercises or computerized programs with various levels of difficulty. Its effects on cognition and functional abilities have been widely studied and reviewed among healthy older adults, ${ }^{12-15}$ in minor neurocognitive disorders, ${ }^{16,17}$ as well as in major neurocognitive disorders. ${ }^{18-20}$ The findings on CT in mild to moderate dementia have been mixed, and recent systematic reviews suggest little or no 
benefit of CT in dementia. ${ }^{19-20}$ Moreover, the quality of current evidence is predominantly low, leading to unclear findings. ${ }^{19-20}$

Some results in functional brain imaging studies have shown positive effects of CT in AD, which suggest training-related brain plasticity. ${ }^{21-23}$ For example, working memory training has been reported to result in several cognitive benefits, as well as changes in relevant functional magnetic resonance imaging responses in early $\mathrm{AD} .^{22}$ While the results are encouraging, this study has methodological limitations, such as non-blinded assessors. ${ }^{22}$ Similarly, a recent Cochrane review brings up the still low methodological quality of randomized controlled trials (RCTs) on CT in dementia. ${ }^{20}$ Furthermore, based on current evidence on the disease progression in AD, it is unclear how training-induced plastic changes might affect the brain pathology, which begins 10-20 years before the onset of overt cognitive symptoms. ${ }^{24}$ However, enhancement of behavioral mechanisms, such as executive function, might benefit the persons with dementia in daily life.

Generalization of the training effects is another presumption of CT: repeated training is assumed to lead to improvements beyond the trained cognitive ability. ${ }^{25}$ According to recent reviews, however, a typical CT-related finding in patients with $\mathrm{AD}$ is a near transfer effect: a post-intervention benefit on a training-specific cognitive outcome, or global cognitive status. ${ }^{19,20}$ Furthermore, evidence on the maintenance of the intervention effects is often lacking. ${ }^{19}$

The Finnish Cognitive Intervention (FINCOG) study is a well-controlled randomized trial with adequate power calculations and two post-intervention assessments to explore clinically meaningful intervention outcomes of cognition, health-related quality of life and psychological well-being (PWB), and the stability of the potential training effects. A systematic, theoretically sound training program was used to evaluate the effectiveness of CT in older patients with mild to moderate 
dementia, still living at home. The training program focused on relevant subskills of executive functioning (i.e. selective attention, working memory, cognitive flexibility and planning), and the trial outcomes included cognitive tasks reflecting these skills.

The primary results of the FINCOG trial on global cognition and health-related quality of life of persons with dementia have been reported elsewhere and showed no effect of CT. ${ }^{26}$ Here we report all the secondary measures of the trial, which include clinically relevant outcomes of executive functioning, attention, working memory, episodic memory, reasoning and PWB of the participants. Our training program was designed to facilitate subskills of executive function, and despite the negative finding in a global cognitive scale, we were interested to find out whether this kind of training has the potential to improve, stabilize, or slow down the decline of specific cognitive skills in older persons with dementia. Prior to our trial, based on the previous RCTs on CT in dementia, we hypothesized that one or two domains of cognitive functioning should have a positive response to $\mathrm{CT}$ if training is effective in this patient population. ${ }^{19}$ However, we did not expect any treatment effect on episodic memory of the participants, who predominantly had a diagnosis of AD. Additionally, we wanted to find out if CT has a positive impact on the PWB of the older persons with dementia.

\section{METHODS}

The FINCOG study is a single-blind, randomized, controlled two-arm trial (an intervention and a treatment-as-usual control group) with a 3-month and 9-month follow-up. A 12-week CT program was run in 14 adult day care centers in Helsinki, Finland, from September 2014 to March 2016. The study design, the enrollment of the participants, the endpoints of the FINCOG trial, and the feasibility of the treatment have been reported previously. ${ }^{27}$ 
Ethical approval was obtained from the Helsinki University Central Hospital ethics committee, and the procedures were planned in accordance with the Declaration of Helsinki. The trial was registered at the Australian and New Zealand Clinical Trials Registry (identifier: ACTRN12614000976684). Informed consent was obtained from each participant before any study procedures began. In cases of reduced judgment capacity (Mini Mental State Examination, MMSE, score $<20),{ }^{28}$ the closest proxy (a spouse or a relative) gave their informed consent.

\section{Participants}

A total of 302 patients with an established dementia diagnosis, and who were attending an adult day care center twice a week in Helsinki, Finland, were invited to take part in the study. Of these, 155 patients (112 women, 43 men) were recruited; they met the inclusion criteria and agreed to participate. The inclusion criteria were: (1) AD or other dementia at a very mild, mild or moderate stage (Clinical Dementia Rating scale, CDR, 0.5 to 2 ); ${ }^{29}$ (2) aged $\geq 65$ years; (3) Finnish-speaking; (4) able to see, hear, read and write; (5) living at home; and (6) attending an adult day care center at least twice a week. The following exclusion criteria were applied: any terminal disease; severe loss of communicative ability; waiting to be institutionalized; and having no available proxy. Those excluded from the trial did not differ from the participants with respect to age or gender. ${ }^{27}$

Figure 1 comprises the flow chart of the trial with the available data at each follow-up point. After the baseline assessment 147 participants were randomized to the intervention group $(n=76)$ and control group $(\mathrm{n}=71)$ using computer-generated randomly allocated numbers received by telephone from a randomization center. To facilitate training in small groups, participants attending a day care center on the same days were randomized in pairs. However, 18 were randomized individually because no trial participants attended a center on the same weekdays. 


\section{[INSERT FIGURE 1 HERE]}

\section{Interventions}

A systematic CT program, based on paper-and-pencil tasks with cognition as a primary target, was designed for the FINCOG trial. The main objective was to train subskills of executive functioning: selective attention, working memory, cognitive flexibility and planning. Our program was a relevant modification of cognitive remediation therapy (CRT), which is a training-based intervention aimed at improving executive functioning among chronic psychiatric patients. ${ }^{30}$ When facilitated by clinicians, CRT is viewed as an evidence-based psychological method in cognitive rehabilitation. ${ }^{31}$ We adjusted the program to fit our older patient population by decreasing the difficulty level of the ready-made CRT tasks, reducing the number of sessions from 40 to 24 , and increasing the font size of the paper-and-pencil tasks. ${ }^{26}$ Rehabilitation techniques of repeated practice, errorless learning (in FINCOG: reducing the opportunity to make errors), immediate feedback, scaffolding (in FINCOG: providing strategies when needed, and gradually increasing task complexity), and facilitating planning before starting a new task were used in the program. ${ }^{30}$ Task examples of FINCOG training are listed in Table 1.

\section{[INSERT TABLE 1 HERE]}

The 12-week CT intervention took place in two 45-minute sessions per week during day care visits. Each session included cognitive exercises from four task categories: visuomotor, perceptual, conceptual, and interactive tasks (e.g. simple word or card games). Interactive tasks were included at the end of each session for up to 10 minutes to keep up the participants' training motivation. Training was tailored according to the participants' cognitive abilities, and was accordingly 
implemented either in small groups of two to four persons or individually when needed (18 cases, due to difficulties in concentration, or lack of a training pair). The difficulty level was tailored during the sessions, but it was not automatic (as in computerized training). Trained psychology students administered CT under the guidance and supervision of an experienced neuropsychologist.

The intervention was feasible in terms of a mean attendance of $22(92 \%)$ sessions, and favorable feedback from the participants and nurses in the adult care centers. ${ }^{27}$ In two of the 14 centers the nurses started their own small-scale cognition-focused activity for their attendees that included 22 FINCOG participants, nine in the intervention group and 13 in the control group. Due to occasional implementation, and quite well balanced distribution of this activity, the participants were kept in their randomized research arms. If there was any self-administered home-based training during the trial, it was not collected.

Both the intervention and control groups received routine treatment at a day care center twice a week for six hours each day. Routine treatment included nonspecific psychosocial (group discussions, musical activities, lunch and coffee), physical (light exercise, walking outdoors), and nonspecific cognitive activities (e.g., orientation to time, simple games, reminiscence of major public events) in groups of 12-16.

\section{Measures}

The severity of dementia and the cognitive status of the participants were assessed at baseline using CDR and MMSE, respectively. The Alzheimer's Disease Assessment Scale - Cognitive subscale $(\mathrm{ADAS}-\mathrm{Cog})^{32}$ was used as a measure of global cognition, as well as in assessing the primary outcome of the trial. ${ }^{26}$ A set of standard neuropsychological tests for executive and cognitive functioning were used as secondary trial outcomes to evaluate the effects of CT on relevant 
cognitive domains. Additionally, the PWB of the participants was assessed by means of a short questionnaire.

- Executive functioning: The total score of the Frontal Assessment Battery (FAB) was used as a global measure of executive functioning. ${ }^{33} \mathrm{FAB}$ is a short, bedside neuropsychological battery, yielding a maximum score of 18 , for assessing patients with neurocognitive disorders to indicate executive dysfunction. ${ }^{33}$ The six tasks explore conceptualization and abstract reasoning, lexical fluency, motor programming, sensitivity to interference, and executive control of action. ${ }^{33}$ The Clock Drawing test (with a range of 0-6 points) of the Consortium to Establish a Registry for Alzheimer's Disease (CERAD) was used as a measure of planning ability, and verbal fluency as an indicator of mental flexibility and cognitive productivity. ${ }^{34}$ Two separate word generation tasks were summarized for a verbal fluency score: lexical (letter $S$ from FAB) and semantic (animal) fluency, both within one minute of time.

- Attention and processing speed: Time (in seconds) in Part A of the Trail Making Test (TMT) was used as a measure of selective attention and speed of mental processing. ${ }^{35}$

- Working memory: A verbal Digit Span task from the Finnish Wechsler Memory Scale, Third Edition (WMS-III) was used as a measure of working memory capacity involving both the forward and the backward conditions. ${ }^{36} \mathrm{~A}$ total score from the two conditions was calculated, yielding a maximum of 32 points.

- Episodic memory: The 12-item Word Recognition task of the ADAS-Cog was used as a measure of episodic memory. ${ }^{32}$ The episodic memory score equals the percentage of correct responses in the first round of the task, in which the 12 studied words are mixed with 12 new words. 
- Reasoning: Verbal concept formation and reasoning were assessed on the Similarities subtest, and visuospatial reasoning was measured by means of Block Design, both from the Wechsler Adult Intelligence Scale, Fourth Edition (WAIS-IV). ${ }^{37}$

- Psychological well-being: The PWB scale includes six questions about life satisfaction, feeling needed, having plans for the future, having a zest for life, feeling depressed, and suffering from loneliness. ${ }^{38}$ These simple questions have been used among older persons with dementia, and have been found easy to understand and to answer. ${ }^{38,39}$ The PWB index score varies between 0 (poor well-being) and 1 (excellent well-being) and can be classified as good $(\mathrm{PWB} \geq .80)$, moderate $(.80>\mathrm{PWB} \geq .40)$ or poor $(\mathrm{PWB}<.40) .{ }^{39}$ In our trial, the PWB responses came from a structured interview with the participant.

Additional cognitive measures for executive functioning (Stroop Test), and attention and processing speed (Coding from the WAIS-IV) were excluded from the neuropsychological test battery. Both measures had missing data at baseline in more than $15 \%$ of the participants due to excessive complexity.

The participants were assessed three times during the trial: at baseline, and at 3 and 9 months. An experienced neuropsychologist who was blind to the group assignment carried out all of the cognitive assessments, except MMSE. Two similarly blinded study nurses assessed the other outcome measures, including MMSE.

\section{Statistical Analyses}

The power calculation of the FINCOG trial was based on the primary cognitive outcome, ADASCog. ${ }^{27} \mathrm{~A}$ four-point change in the ADAS-Cog was considered a clinically meaningful difference between the intervention and the control group. ${ }^{27,40}$ Therefore, a sample size of 64 per group was 
calculated to ensure $80 \%$ power to detect this difference with a standard deviation of 8 and a type I error rate of $5 \%$. An estimated dropout rate was $20 \%$ during the follow-up. An intention-to-treat analysis was applied: all participants assessed at baseline and in at least one of the follow-ups were included in the analyses.

The data are presented as means with standard deviations for the continuous variables, and as numbers and percentages for the categorical variables. Statistical comparison between the groups at baseline was determined by means of a t-test, a permutation test or a Chi-square test, as appropriate.

The mean changes between the baseline and 3-month measures were assessed using bootstrap type analysis of covariance (ANCOVA), with age, gender, educational level and baseline measure as covariates; $95 \%$ confidence intervals $(\mathrm{CI})$ were obtained by means of bias-corrected bootstrapping (5,000 replications). The standardized response mean (SRM; mean change/SD of change) of each cognitive measure between the baseline and 3-month assessments was used to compare the responsiveness of different cognitive domains to the intervention. Effect size $(d)$ was calculated by using the method of Cohen. CIs for the SRM and effect sizes were obtained by means of biascorrected bootstrapping (5,000 replications). The normality of the variables was evaluated using the Shapiro-Wilk $W$ test. Stata Statistical Software (Release 15.0, StataCorp, College Station, Texas) was used for the statistical analyses.

\section{RESULTS}

\section{Baseline comparisons}

There were no differences between the intervention and control group in the participants' baseline characteristics: demographics (age, sex, and education), self- or proxy-rated functional 
characteristics (living alone, daily activities, self-rated psychological well-being), and clinical characteristics (dementia diagnoses, CDR, MMSE, comorbidities, and number of medications). ${ }^{27}$ Table 1 gives the details. The mean age of the 147 participants was 83.1 years, $71 \%$ were female, and the mean MMSE score was 20. According to the CDR, 37\% of the randomized participants had moderate dementia (CDR 2), 53\% were at a mild stage (CDR 1), and only $10 \%$ were at a very mild stage (CDR 0.5). The primary clinical diagnosis of dementia was AD in 122 participants (NINCSADRDA criteria). ${ }^{41}$ The mean PWB score of 0.75 indicated moderate psychological well-being at baseline.

In addition, Table 2 shows the cognitive and psychological outcome measures at baseline. Participants in the intervention and the control groups differed significantly on one cognitive measure, the $\mathrm{FAB}$, with those in the intervention group scoring slightly higher than those in the control group. However, both groups had a mean score of less than 12, which indicates executive dysfunction. $^{42}$

[INSERT TABLE 2 HERE]

\section{Effects of the intervention on cognitive functioning}

As Table 3 shows, there were no differences between the two groups in the change for any cognitive measure over three months (adjusted for age, sex, educational level, and respective baseline measure). Additional analyses without the 13 control participants who participated in occasional "extra training" did not change the finding in any cognitive measure (data not shown). Figure 2 shows the SRMs of the different cognitive measures in both groups between pre- and posttreatment assessments. The responses of the cognitive outcomes did not differ from each other. 
[INSERT TABLE 3 HERE]

\section{[INSERT FIGURE 2 HERE]}

We further explored whether patients with mild dementia (CDR 0.5-1) would benefit from CT. In subgroup analyses with 49 participants in the intervention group and 43 participants in the control group the responses of seven cognitive outcomes (FAB, Clock Test, Fluency, Digit Span, Recognition, Similarities and Block Design) did not differ between the groups at 3 months. The mean time for the Trail Making test, Part A (i.e. TMT) increased in the intervention group by 7 seconds (95\% CI $=-4$ to 19$)$ and decreased in the control group by 8 seconds (95\% $\mathrm{CI}=-19$ to 2$)$ at 3 months ( $p=.026$, adjusted for age, sex, educational level and baseline measure). However, the mean time and standard deviation for both the intervention group $(\mathrm{M}=137, \mathrm{SD} 63)$, and the control group $(\mathrm{M}=143, \mathrm{SD}=60)$ already show severe difficulties in task performance of TMT at baseline, resulting in large variance across participants, which may explain this unexpected finding.

\section{Effects of the intervention on psychological well-being}

There were no differences between the two groups in the extent of change in PWB over time. A positive trend at 3 months was observed for the intervention group: the PWB score declined from the baseline by $-0.01(95 \% \mathrm{CI}=-0.04$ to 0.02$)$ in the intervention group, whereas the respective change in the control group was $-0.06(95 \% \mathrm{CI}=-0.10$ to -0.02$)$, but no significant interaction effect was found ( $p=.079, d=-0.31)$. The PWB score returned close to baseline score in both groups at 9 months.

[INSERT FIGURE 3 HERE] 


\section{DISCUSSION}

The FINCOG trial examined the effectiveness of a systematic 12-week CT program on secondary trial outcomes of cognition and PWB in community-dwelling older adults with mild to moderate dementia. Training was specifically designed to remediate subskills of executive functioning: selective attention, working memory, cognitive flexibility, and planning. No beneficial effects were found in attention, working memory, episodic memory, executive functions, reasoning, or PWB after the training. We expected the difference in cognitive functioning to be highest right after the intervention. When no differences were found between the intervention and control group at 3 months, we did not test the differences at 9 months. A weak trend at the post-intervention assessment suggested a change in PWB favoring the intervention group, but the difference between the two groups was not statistically significant. Additionally, PWB returned close to baseline in both groups at 9 months. Similarly, our previously reported primary FINCOG outcomes of global cognition and health-related quality of life showed no beneficial effect of CT. ${ }^{26}$

The pragmatic nature of our study is one of its strengths but may partially explain the negative findings. We kept the exclusion criteria to a minimum, allowed various dementia diagnoses, both mild and moderate stages of dementia, as well as very old persons with comorbid conditions. The FINCOG participants were a bit older and had a higher number of comorbidities and disabilities than those in many previous dementia studies. ${ }^{19}$ At the same time, our trial included individuals in somewhat more advanced stages of the disease than in previous trials, where the participants were typically at a mild stage of dementia. ${ }^{19}$ Positive effects of CT might be easier to achieve in earlier stages of dementia, or even before the actual onset of dementia as shown in some previous trials. $^{17,22,43}$ 
Both the control and intervention group attended day care activities during the trial, i.e. received regular cognitive activation in peer groups, which has shown efficacy in terms of cognitive status and some aspects of well-being in dementia, and may have attenuated the effects of FINCOG training. ${ }^{44}$ Adult day care activity did include orientation to time, voluntary and nonspecific games, reminiscence of major public events and so forth, but there were no structured therapy sessions. FINCOG training was based on systematic and supervised paper-and-pencil exercises with increasing difficulty, whereas a genuinely adaptive computerized program might have had larger training effects. ${ }^{43,46}$ Training was performed in small groups. A recent study comparing groupbased CT with individual-based training suggests that the latter might be more effective. ${ }^{45}$ However, our CT program was conducted in groups of two to four participants, thus ensuring sufficient support for the participants to understand the task instructions.

Positive effects of CT on executive functions of patients with dementia have occasionally been reported in previous RCTs. One study on computerized structured CT (90 minutes a week in three sessions over 12 weeks) showed improvement in cognitive outcomes, including tests of executive function and working memory. ${ }^{43} \mathrm{~A}$ total of 80 participants in this study were early-stage $\mathrm{AD}$ patients with no common comorbidities of old age. Training was administered individually together with a neuropsychologist, whereas in our trial it took place in small groups. Another highly intensive program with five repeated cycles of CT (one cycle: 20 sessions in four weeks) involving a small group of $\mathrm{AD}$ patients resulted in improved performance on several cognitive outcomes after one year of training. ${ }^{47}$ Moreover, a few small-scale RCTs have reported CT benefits with regard to working memory, ${ }^{22,48}$ decision making, ${ }^{49}$ and verbal conceptualization, ${ }^{50}$ but these findings need to be confirmed. 
Psychological well-being was evaluated as moderate before the FINCOG intervention, but contrary to our predictions, no change for the better was observed at post-intervention. There was a weak trend following the intervention indicating that stability in PWB favored the intervention group, but the difference between the two groups was not statistically or clinically significant. To our knowledge, only three previous small-scale RCTs have reported a benefit of CT on mood. ${ }^{51-53} \mathrm{~A}$ positive impact was observed after a short individual memory program (six sessions) focusing on autobiographical memories, which may have evoked positive thoughts and improved moods among the participants. ${ }^{51}$ Additionally, given priority to a therapist-led intervention over a computerassisted condition, ${ }^{52}$ as well as psychological support over cognitive activities, ${ }^{53}$ has resulted in beneficial effects on mood.

Despite the negative findings, the present study has several strengths. The FINCOG study comprises a randomized, single-blind, two-arm controlled trial, with separate research personnel conducting assessments and interventions. With 147 participants randomized in the two arms, the sample size was larger than in most previous CT trials in dementia. ${ }^{19}$ We conducted a detailed neuropsychological assessment and found no substantive differences between the groups in terms of demographic characteristics, cognitive or psychological status before the intervention. A small difference in FAB favored the intervention group at baseline; however, the baseline values were used as covariates in the analyses. Cognitive intervention was theoretically justified, carefully planned and executed to meet the cognitive abilities of the target population. The training was regular, quite intensive and well accepted by the participants; adherence was good in the intervention arm. ${ }^{27}$

The current results are consistent with those reported in a large multicenter trial in France (ETNA3), involving three different cognition-based interventions and a control condition, and 
including a total of 653 Alzheimer's patients: no effects of CT on cognition or depressive symptoms compared to a control group were found. ${ }^{45}$ As in our trial, the ETNA3 training took place in small groups and focused on various cognitive functions. Furthermore, active training took place once a week for 90 minutes over period of three months. ${ }^{45}$ Thus, our results, with more frequent training, support these findings.

Overall, the results of the FINCOG trial add to the evidence of the ineffectiveness of CT in dementia, which has recently also been noticed in clinical guidelines for dementia care. ${ }^{54}$ The trial was based on rigorous RCT methodology, was conducted in a real-world setting, and involved a large group of older adults with mild to moderate dementia. Systematic CT delivered in 24 sessions had no effect on domain-specific cognitive functioning or PWB of the community-dwelling patients. Therefore, the neuropsychological findings of the FINCOG trial do not support the effectiveness of CT among patients with established dementia.

\section{ACKNOWLEDGMENTS}

This work was supported by the Päivikki and Sakari Sohlberg Foundation; the Finnish Brain Foundation; and the Helsinki University Central Hospital. The funding organizations had no role in study design, data collection and analysis, decision to publish, or preparation of the manuscript.

\section{DISCLOSURE OF INTEREST}

The authors report no conflict of interest.

\section{REFERENCES}

1. Wimo A, Guerchet M, Ali GC, et al. The worldwide costs of dementia 2015 and comparisons with 2010. Alzheimer's \& Dementia. 2017;13(1):1-7.

2. Nelson L, Tabet N. Slowing the progression of Alzheimer's disease; what works? Ageing Research Reviews. 2015;23:193-209. 
3. Rockwood K, Moorhouse PK, Song X, et al. Disease progression in vascular cognitive impairment: cognitive, functional and behavioural outcomes in the Consortium to Investigate Vascular Impairment of Cognition (CIVIC) cohort study. Journal of the neurological sciences. 2007;252(2):106-112.

4. Weintraub S, Wicklund AH, Salmon DP. The Neuropsychological Profile of Alzheimer Disease. Cold Spring Harbor Perspectives in Medicine. 2012;2(4).

5. McKeith IG, Dickson DW, Lowe J, et al. Diagnosis and management of dementia with Lewy bodies: third report of the DLB Consortium. Neurology. 2005;65(12):1863-1872.

6. Diamond A. Executive functions. Annual Review of Psychology. 2013;64:135-168.

7. Miyake A, Friedman NP, Emerson MJ, Witzki AH, Howerter A, Wager TD. The unity and diversity of executive functions and their contributions to complex "Frontal Lobe" tasks: a latent variable analysis. Cognitive Psychology. 2000;41(1):49-100.

8. Martyr A, Clare L. Executive function and activities of daily living in Alzheimer's disease: a correlational meta-analysis. Dementia and Geriatric Cognitive Disorders. 2012;33(2-3):189-203. 9. Clare L, Woods RT. Cognitive training and cognitive rehabilitation for people with early-stage Alzheimer's disease: a review. Neuropsychological Rehabilitation. 2004;14:385-401.

10. Choi J, Twamley EW. Cognitive rehabilitation therapies for Alzheimer's disease: A review of methods to improve treatment engagement and self-efficacy. Neuropsychology Review. 2013;23:4862.

11. Mowszowski L, Batchelor J, Naismith SL. Early intervention for cognitive decline: can cognitive training be used as a selective prevention technique? International Psychogeriatrics. 2010;22(4):537-548.

12. Lampit A, Hallock $\mathrm{H}$, Valenzuela M. Computerized cognitive training in cognitively healthy older adults: a systematic review and meta-analysis of effect modifiers. PLOS Medicine. 2014;11(11):e1001756.

13. Reijnders J, van Heugten C, van Boxtel M. Cognitive interventions in healthy older adults and people with mild cognitive impairment: A systematic review. Ageing Research Reviews. 2013;12:263-275.

14. Smith GE, Housen P, Yaffe K, et al. A Cognitive Training Program Based on Principles of Brain Plasticity: Results from the Improvement in Memory with Plasticity-based Adaptive Cognitive Training (IMPACT) Study. Journal of the American Geriatrics Society. 2009;57(4):594603.

15. Willis SL, Tennstedt SL, Marsiske M, et al. Long-term effects of cognitive training on everyday functional outcomes in older adults. JAMA. 2006;296(23):2805-2814.

16. Huckans M, Hutson L, Twamley E, Jak A, Kaye J, Storzbach D. Efficacy of cognitive rehabilitation therapies for mild cognitive impairment (MCI) in older adults: working toward a theoretical model and evidence-based interventions. Neuropschology Review. 2013;23(1):63-80. 17. Sherman DS, Mauser J, Nuno M, Sherzai D. The Efficacy of Cognitive Intervention in Mild Cognitive Impairment (MCI): a Meta-Analysis of Outcomes on Neuropsychological Measures. Neuropsychology Review. 2017;27(4):440-484.

18. Leung IH, Walton CC, Hallock H, Lewis SJ, Valenzuela M, Lampit A. Cognitive training in Parkinson disease: A systematic review and meta-analysis. Neurology. 2015;85(21):1843-1851.

19. Kallio EL, Öhman H, Kautiainen H, Hietanen M, Pitkälä K. Cognitive Training Interventions for Patients with Alzheimer's Disease: A Systematic Review. Journal of Alzheimer's Disease. 2017;56(4):1349-1372.

20. Bahar-Fuchs A, Martyr A, Goh AMY, Sabates J, Clare L. Cognitive training for people with mild to moderate dementia. Cochrane Database of Systematic Reviews. 2019(3).

21. Spironelli C, Bergamaschi S, Mondini S, Villani D, Angrilli A. Functional plasticity in Alzheimer's disease: effect of cognitive training on language-related ERP components. Neuropsychologia. 2013;51(8):1638-1648. 
22. Huntley JD, Hampshire A, Bor D, Owen A, Howard RJ. Adaptive working memory strategy training in early Alzheimer's disease: randomised controlled trial. The British Journal of Psychiatry. 2017;210(1):61-66.

23. Barban F, Mancini M, Cercignani M, et al. A Pilot Study on Brain Plasticity of Functional Connectivity Modulated by Cognitive Training in Mild Alzheimer's Disease and Mild Cognitive Impairment. Brain Sciences. 2017;7(5):50.

24. Beason-Held LL, Goh JO, An Y, et al. Changes in brain function occur years before the onset of cognitive impairment. The Journal of neuroscience : the official journal of the Society for Neuroscience. 2013;33(46):18008-18014.

25. Rabipour S, Raz A. Training the brain: fact and fad in cognitive and behavioral remediation. Brain Cogn. 2012;79(2):159-179.

26. Kallio E-L, Öhman H, Hietanen M, et al. Effects of Cognitive Training on Cognition and Quality of Life of Older Persons with Dementia. Journal of the American Geriatrics Society. 2018;66(4):664-670.

27. Kallio EL, Öhman H, Carlson S, Kautiainen H, Hietanen M, Pitkälä KH. Feasibility and baseline findings of a Finnish cognitive training (FINCOG) intervention in a randomised controlled trial among community-dwelling persons with dementia. European Geriatric Medicine.

2017;8(3):245-249.

28. Folstein MF, Folstein SE, McHugh PR. 'Mini-mental state' a practical method for grading the cognitive state of patients for the clinician. Journal of Psychiatric Research. 1975;12:189-198.

29. Hughes CP, Berg L, Danziger WL, Coben LA, Martin RL. A new clinical scale for the staging of dementia. British Journal of Psychiatry 1982;140:566-572.

30. Delahunty A, Morice R. Toiminnanohjauksen ohjelma [Frontal/Executive Program. A Manual for Neurocognitive Rehabilitation for Patients with Chronic Schizophrenia]. Albury, NSW: Mental Health Unit, South West health Districts; 1993.

31. Wykes T, Huddy V, Cellard C, McGurk S, Czobor P. A Meta-Analysis of Cognitive Remediation for Schizophrenia: Methodology and Effect Sizes. American Journal of Psychiatry. 2011;168(5):472-485.

32. Rosen WG, Mohs RC, Davis KL. A new rating scale for Alzheimer's disease. American Journal of Psychiatry. 1984;141:1356-1364.

33. Dubois B, Slachevsky A, Litvan I, Pillon B. The FAB: A frontal assessment battery at bedside. Neurology. 2000;55:1621-1626.

34. Sotaniemi M, Pulliainen V, Hokkanen L, et al. CERAD-neuropsychological battery in screening mild Alzheimer's disease. Acta Neurologica Scandinavica. 2012;125(1):16-23.

35. Reitan RM. The relation of the Trail Making Test to organic brain damage. Journal of

Consulting Psychology. 1955;19:393-394.

36. Wechsler D. WMS-III käsikirja. [Wehsler Memory Scale - Third Edition]. Helsinki:

Psykologien Kustannus Oy; 2008.

37. Wechsler D. WAIS-IV käsikirja. [Wehsler Adult Intelligence scale - Fourth Edition]. Helsinki: Psykologien Kustannus Oy; 2012.

38. Routasalo PE, Tilvis RS, Kautiainen H, Pitkala KH. Effects of psychosocial group rehabilitation on social functioning, loneliness and well-being of lonely, older people: randomized controlled trial. Journal of Advanced Nursing. 2009;65:297-305.

39. Muurinen S, Savikko N, Soini H, Suominen M, Pitkälä K. Nutrition and psychological wellbeing among long-term care residents with dementia. The Journal of Nutrition, Health \& Aging. 2015;19(2):178-182.

40. Kaduszkiewicz H, Zimmermann T, Beck-Bornholdt HP, van den Bussche H. Cholinesterase inhibitors for patients with Alzheimer's disease: systematic review of randomised clinical trials. The British Medical Journal. 2005;331(7512):321-327. 
41. McKhann GM, Knopman DS, Chertkow H, et al. The diagnosis of dementia due to Alzheimer's disease: recommendations from the National Institute on Aging-Alzheimer's Association workgroups on diagnostic guidelines for Alzheimer's disease. Alzheimers Dement. 2011;7(3):263269.

42. Slachevsky A, Villalpando J, Sarazin M, Hahn-Barma V, Pillon B, Dubois B. Frontal assessment battery and differential diagnosis of frontotemporal dementia and alzheimer disease. Archives of Neurology. 2004;61(7):1104-1107.

43. Cavallo M, Hunter E, van der Hiele K, Angilletta C. Computerized structured cognitive training in patients affected by early-stage Alzheimer's disease is feasible and effective: A randomized controlled study. Archives of Clinical Neuropsychology. 2016;31:868-876.

44. Aguirre E, Woods RT, Spector A, Orrell M. Cognitive stimulation for dementia: A systematic review of the evidence of effectiveness from randomised controlled trials. Ageing Research Reviews. 2013;12:253-262.

45. Amieva H, Robert PH, Grandoulier A, et al. Group and individual cognitive therapies in Alzheimer's disease: the ETNA3 randomized trial. International Psychogeriatrics. 2016;28(5):707717.

46. Garcia-Casal JA, Loizeau A, Csipke E, Franco-Martin M, Perea-Bartolome MV, Orrell M. Computer-based cognitive interventions for people living with dementia: a systematic literature review and meta-analysis. Aging \& Mental Health. 2017;21(5):454-467.

47. Bergamaschi S, Arcara G, Calza A, Villani D, Orgeta V, Mondini S. One-year repeated cycles of cognitive training (CT) for Alzheimer's disease. Aging Clinical and Experimental Research. 2013;25(4):421-426.

48. Jelcic N, Cagnin A, Meneghello F, Turolla A, Ermani M, Dam M. Effects of lexical-semantic treatment on memory in early Alzheimer disease: an observer-blinded randomized controlled trial. Neurorehabilitation and Neural Repair. 2012;26(8):949-956.

49. Gaitán A, Garolera M, Cerulla N, Chico G, Rodriguez-Querol M, Canela-Soler J. Efficacy of an adjunctive computer-based cognitive training program in amnestic mild cognitive impairment and Alzheimer's disease: a single-blind, randomized clinical trial. International Journal of Geriatric Psychiatry. 2013;28(1):91-99.

50. Kawashima R, Okita K, Yamazaki R, et al. Reading aloud and arithmetic calculation improve frontal function of people with dementia. The Journals of Gerontology Series A, Biological Sciences and Medical Sciences. 2005;60(3):380-384.

51. Lalanne J, Gallarda T, Piolino P. 'The castle of remembrance': New insights from a cognitive training programme for autobiographical memory in Alzheimer's disease. Neuropsychological Rehabilitation. 2015;25(2):254-282.

52. Lee GY, Yip CC, Yu EC, Man DW. Evaluation of a computer-assisted errorless learning-based memory training program for patients with early Alzheimer's disease in Hong Kong: a pilot study. Clinical Interventions in Aging. 2013;8:623-633.

53. Niu Y, Tan J, Guan J, Zhang Z, L W. Cognitive stimulation therapy in the treatment of neuropsychiatric symptoms in Alzheimer's disease: a randomized controlled trial. Clinical Rehabilitation. 2010;24:1102-1111.

54. Pink J, O’Brien J, Robinson L, Longson D. Dementia: assessment, management and support: summary of updated NICE guidance. BMJ. 2018;361:k2438. 


\section{TABLES}

Table 1. An overview of the FINCOG training program

\begin{tabular}{|c|c|c|c|c|}
\hline $\begin{array}{l}\text { Cognitive } \\
\text { domain }\end{array}$ & $\begin{array}{l}\text { Selective } \\
\text { attention }\end{array}$ & $\begin{array}{l}\text { Working } \\
\text { memory }\end{array}$ & $\begin{array}{l}\text { Cognitive } \\
\text { flexibility }\end{array}$ & Planning \\
\hline $\begin{array}{l}\text { Cognitive } \\
\text { task } \\
\text { examples }\end{array}$ & $\begin{array}{l}\text { Visual search; } \\
\text { Cancellation } \\
\text { tasks with } \\
\text { alternating } \\
\text { objects; } \\
\text { Searching for } \\
\text { letters and } \\
\text { making words of } \\
\text { them; } \\
\text { Overlapping } \\
\text { figures }\end{array}$ & $\begin{array}{l}\text { Counting objects } \\
\text { while searching } \\
\text { for them; } \\
\text { Basic arithmetic; } \\
\text { Simple n-back } \\
\text { tasks with } \\
\text { playing cards; } \\
\text { Following verbal } \\
\text { instructions; } \\
\text { Reading aloud a } \\
\text { short text and } \\
\text { answering } \\
\text { questions }\end{array}$ & $\begin{array}{l}\text { Cancellation } \\
\text { tasks with } \\
\text { changing rules; } \\
\text { Organizing } \\
\text { numbers from } \\
\text { the lowest to the } \\
\text { highest; } \\
\text { Categorizing } \\
\text { words and } \\
\text { playing cards } \\
\text { under a simple } \\
\text { rule; } \\
\text { Taking turns in } \\
\text { interactive word- } \\
\text { finding tasks }\end{array}$ & $\begin{array}{l}\text { Before starting } \\
\text { any cognitive } \\
\text { task, a } \\
\text { participant was } \\
\text { asked to stop and } \\
\text { think about the } \\
\text { best way of } \\
\text { completing it }\end{array}$ \\
\hline
\end{tabular}

FINCOG, Finnish Cognitive Intervention 
Table 2. Demographic and clinical characteristics of the participants in the FINCOG trial.

\begin{tabular}{|c|c|c|c|}
\hline Characteristics & $\begin{array}{l}\text { Intervention Group } \\
(n=76)\end{array}$ & $\begin{array}{l}\text { Control Group } \\
(n=71)\end{array}$ & $P$-value \\
\hline Age, mean (SD) & $82.6(5.5)$ & $83.6(5.4)$ & 0.24 \\
\hline Female, $\%$ & 65.8 & 78.9 & 0.08 \\
\hline Education $<8$ years, $\%$ & 42.1 & 50.7 & 0.30 \\
\hline $\begin{array}{l}\text { CDR, \% } \\
0.5 \\
1 \\
2 \\
\text { MMSE, mean (SD) }\end{array}$ & $\begin{array}{l}11.8 \\
52.6 \\
35.5 \\
21.0(4.3)\end{array}$ & $\begin{array}{l}8.5 \\
52.1 \\
39.4 \\
19.9(3.9)\end{array}$ & 0.75 \\
\hline $\begin{array}{l}\text { Dementia diagnosis, \% } \\
\text { AD } \\
\text { Vascular } \\
\text { Parkinson's or Lewy body } \\
\text { Other } \\
\text { Charlson index mean (SD) }\end{array}$ & $\begin{array}{r}76.3 \\
10.5 \\
3.9 \\
9.2 \\
2.7(16)\end{array}$ & $\begin{array}{r}90.1 \\
4.2 \\
1.4 \\
4.2 \\
2.8(19)\end{array}$ & 0.17 \\
\hline Number of medications, mean (SD) & $8.2(3.2)$ & $7.8(3.0)$ & 0.34 \\
\hline On $\mathrm{AD}$ medication, $\%$ & 78.9 & 87.4 & 0.54 \\
\hline On anticholinergics, $\%$ & 43.4 & 52.1 & 0.29 \\
\hline Living alone, $\%$ & 71.1 & 70.4 & 0.93 \\
\hline $\begin{array}{l}\text { Daily activities (CDR, Personal care), \% } \\
\text { Full capable }(0.5) \\
\text { Needs prompting }(1) \\
\text { Requires assistance }(2-3)\end{array}$ & $\begin{array}{l}19.7 \\
40.8 \\
39.5\end{array}$ & $\begin{array}{l}21.1 \\
33.8 \\
45.0\end{array}$ & 0.67 \\
\hline $\begin{array}{l}\text { Executive functioning, mean (SD) } \\
\text { FAB, total score } \\
\text { Clock Test (CERAD) } \\
\text { Verbal Fluency, total score }\end{array}$ & $\begin{array}{l}11.2(2.8) \\
2.8(1.6) \\
17.7(8.0)\end{array}$ & $\begin{array}{l}10.2(2.8) \\
2.5(1.4) \\
15.9(7.8)\end{array}$ & $\begin{array}{l}0.03^{*} \\
0.21 \\
0.16\end{array}$ \\
\hline $\begin{array}{l}\text { Attention, mean (SD) } \\
\text { TMT, Part A, time (s) }\end{array}$ & $145(63)$ & $155(72)$ & 0.37 \\
\hline $\begin{array}{l}\text { Working memory, mean (SD) } \\
\text { Digit Span, total score (WMS III) }\end{array}$ & $13.1(3.2)$ & $12.4(3.0)$ & 0.14 \\
\hline $\begin{array}{l}\text { Episodic memory, mean (SD) } \\
\text { Recognition, \% (ADAS-Cog) }\end{array}$ & $67.3(13.2)$ & $65.1(13.2)$ & 0.33 \\
\hline $\begin{array}{l}\text { Reasoning, mean (SD) } \\
\text { Similarities (WAIS-IV) } \\
\text { Block Design (WAIS-IV) }\end{array}$ & $\begin{array}{l}15.1(6.8) \\
14.4(8.2)\end{array}$ & $\begin{array}{l}13.3(6.6) \\
14.6(8.6)\end{array}$ & $\begin{array}{l}0.11 \\
0.89\end{array}$ \\
\hline PWB, mean (SD) & $0.75(0.16)$ & $0.76(0.18)$ & 0.32 \\
\hline
\end{tabular}

AD, Alzheimer's Disease; CDR, Clinical Dementia Rating; CERAD, the Consortium to Establish a Registry for Alzheimer's Disease; FAB, Frontal Assessment Battery; FINCOG, Finnish Cognitive Intervention; MMSE, Mini-Mental State Examination; PWB, Psychological Well-Being Scale; s, Seconds; SD, standard deviation; TMT, Trail Making Test; WAIS-IV, Wechsler Adult Intelligence Scale-Fourth Edition; WMS III, Wechsler Memory Scale-Third Edition

$* p<0.05$ 
Table 3. Comparisons of mean changes in cognitive measures from baseline to three months in the intervention and control groups (adjusted for age, sex, educational level and baseline measure).

\begin{tabular}{|c|c|c|c|c|}
\hline Cognitive & Intervention Group & Control Group & $P-$ & \\
\hline Measure & Mean Change $(95 \% \mathrm{CI})$ & Mean Change $(95 \% \mathrm{CI})$ & value & Effect Size (95\% CI) \\
\hline FAB & $-0.1(-0.6$ to 0.4$)$ & $0.0(-0.5$ to 0.5$)$ & 0.96 & $0.07(-0.26$ to 0.39$)$ \\
\hline Clock Test & $0.12(-0.23$ to 0.47$)$ & $0.06(-0.30$ to 0.41$)$ & 0.47 & $-0.04(-0.37$ to 0.29$)$ \\
\hline Fluency & $-0.5(-1.5$ to 0.5$)$ & $-0.2(-1.4$ to 1.1$)$ & 0.98 & $0.06(-0.27$ to 0.39$)$ \\
\hline TMT & $7(-4$ to 17$)$ & $-6(-15$ to 4$)$ & 0.09 & $-0.29(-0.64$ to 0.05$)$ \\
\hline Digit Span & $0.1(-0.4$ to 0.7$)$ & $-0.3(-0.8$ to 0.2$)$ & 0.09 & $-0.20(-0.55$ to 0.15$)$ \\
\hline Recognition & $-1.9(-4.3$ to 0.5$)$ & $-2.2(-5.1$ to 0.7$)$ & 0.41 & $-0.03(-0.36$ to 0.30$)$ \\
\hline Similarities & $0.6(-0.3$ to 1.5$)$ & $0.4(-0.7$ to 1.5$)$ & 0.30 & $-0.05(-0.39$ to 0.28$)$ \\
\hline Block Design & $-0.2(-1.7$ to 1.3$)$ & $-0.8(-2.2$ to 0.7$)$ & 0.40 & $-0.10(-0.44$ to 0.25$)$ \\
\hline
\end{tabular}

CI, confidence interval; FAB, Frontal Assessment Battery; TMT, Trail-Making Test. 
FIGURES

Figure 1. Flowchart of the FINCOG trial (adapted from Kallio et al., 2018 26 )

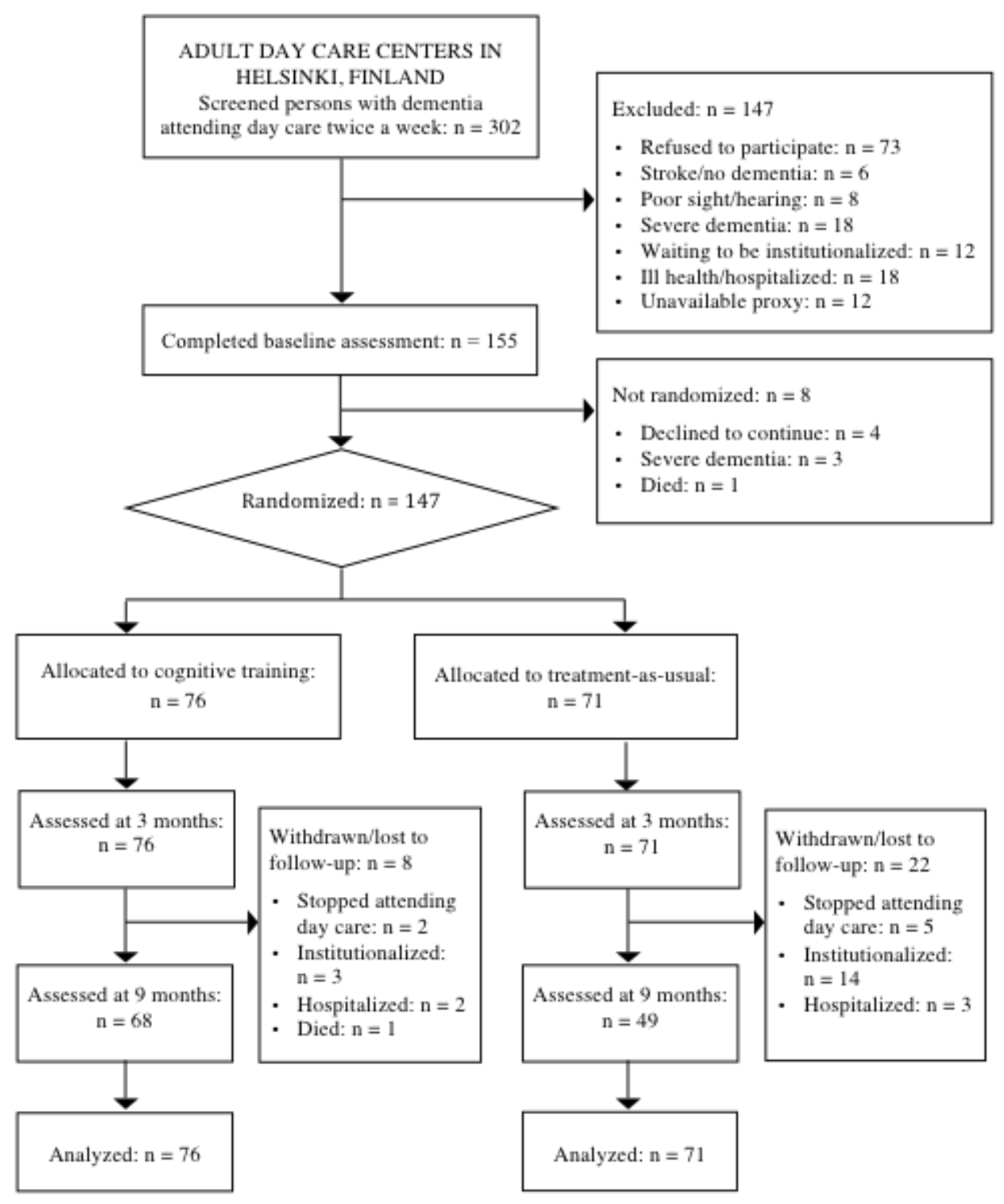


Figure 2. Standardized response means (SRMs) from baseline to 3-month assessment in cognitive outcomes in the intervention and control groups. For the purpose of comparing the changes, the standardized response mean (mean change/SD of change) of each measure was applied.

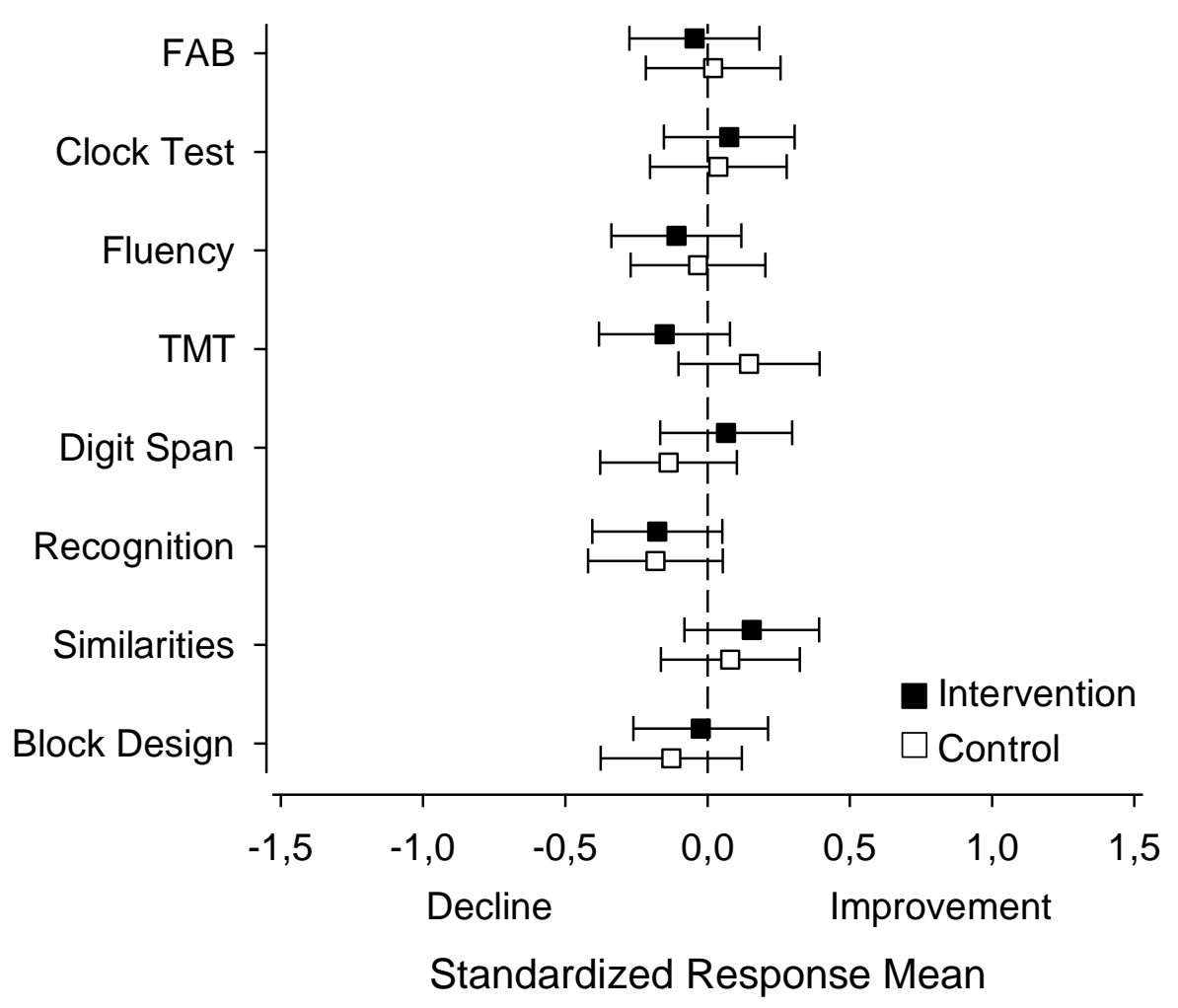


Figure 3. Mean changes in the intervention and control groups in psychological well-being (PWB) relative to baseline at 3-month and 9-month assessment points (adjusted for age and sex). The range of PWB scores is $0-1$, and higher scores indicate greater well-being.

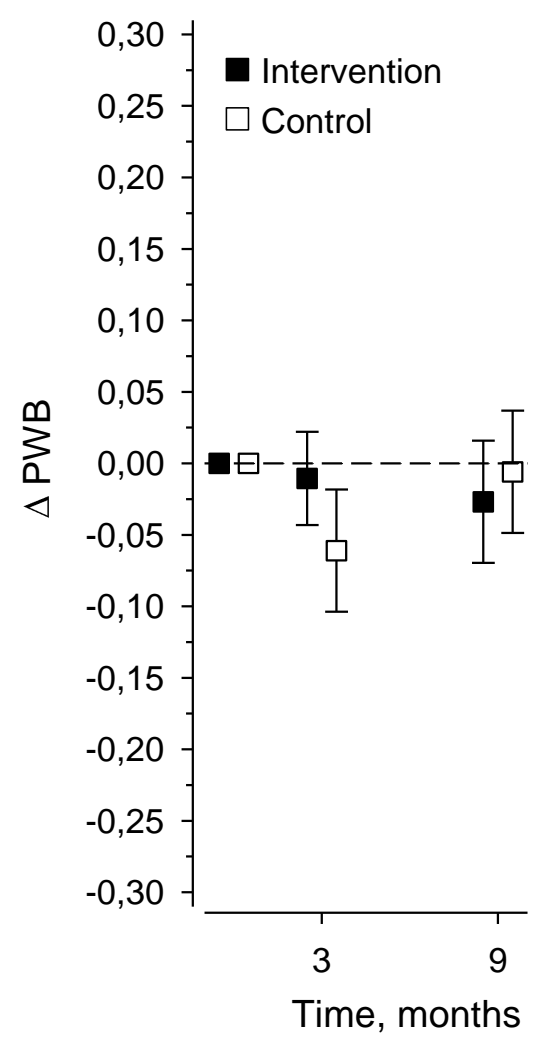

